\title{
Whole-mount fluorescence in situ hybridization to visualize symbiotic bacteria in the gills of deep-sea mussels
}

\author{
Masaru Fujinoki ${ }^{1,2}$, Tomoko Koito ${ }^{1,2,3}$, Yoshihiro Fujiwara ${ }^{4}$, Masaru Kawato ${ }^{4}$, \\ Yuya Tada ${ }^{2}$, Koji Hamasaki ${ }^{2}$, Mitsuru Jimbo ${ }^{5}$, Koji Inoue ${ }^{2,1, *}$ \\ ${ }^{1}$ Department of Natural Environmental Studies, Graduate School of Frontier Sciences, The University of Tokyo, Kashiwa, \\ Chiba 277-8561, Japan \\ ${ }^{2}$ Atmosphere and Ocean Research Institute, The University of Tokyo, Kashiwa, Chiba 277-8564, Japan \\ ${ }^{3}$ College of Bioresource Sciences, Nihon University, Fujisawa, Kanagawa 252-0880, Japan \\ ${ }^{4}$ Japan Agency for Marine-Earth Science and Technology, Yokosuka, Kanagawa 237-0061, Japan \\ ${ }^{5}$ School of Marine Biosciences, Kitasato University, Sagamihara, Kanagawa 252-0373, Japan
}

\begin{abstract}
Fluorescence in situ hybridization (FISH) is a technique used to visualize the distribution of specific nucleotide sequences. For the purpose of detecting symbiotic bacteria in the tissues of host organisms, FISH is usually performed on paraffin or frozen sections of host tissues. However, the sectioning process requires lengthy procedures and sectioning restricts observations to a particular plane. To solve these problems, we attempted FISH on whole gill filaments of deep-sea mussels of the genus Bathymodiolus. Isolated gill filaments of $B$. septemdierum and B. platifrons were fixed with paraformaldehyde, hybridized in microcentrifuge tubes containing labeled probes specific to either thiotrophic or methanotrophic symbionts, mounted on glass slides and then observed under a fluorescent microscope. The distribution of the symbionts was clearly visualized; fluorescence signals, packed in the bacteriocytes, occupied most parts of the gill surface. However, fluorescence signals were not observed in the ciliary cells lining the ventral edge of the filaments nor in ciliary junctions. Differences in the morphology of the bacteriocytes harbored by the 2 species were observed under a confocal laser scanning microscope: attached polygonal bacteriocytes in $B$. septemdierum and detached round particles in $B$. platifrons. Thus, the whole-mount FISH technique was demonstrated to be useful for wide-scale observation of symbiotic bacteria in the host cells.
\end{abstract}

KEY WORDS: Fluorescence in situ hybridization · FISH · Bathymodiolus · Chemosynthetic bacteria $\cdot$ Endosymbiont $\cdot$ Symbiosis

\section{INTRODUCTION}

Fluorescence in situ hybridization (FISH) is a technique used to detect a specific nucleotide sequence by using oligodeoxynucleotide or RNA probes, which are complementary to the target sequence and labeled with fluorescent dyes (Amann et al.
1995). In the field of marine ecology, it is regarded as an effective technique to detect and locate specific species or strains of bacteria in the environment and also in animal tissues (Bouvier \& Del Giorgio 2003). For example, Duperron et al. (2007) used this technique to localize and differentially visualize thiotrophic and methanotrophic endosymbionts in 
the gills of deep-sea mussels of the genus Bathymodiolus.

In the present study, we propose a new technique of FISH, i.e. hybridization on the whole, unsectioned gill filament of bathymodiolin mussels. In previous studies, FISH has been performed on histological sections of the gill filaments (Duperron et al. 2007), which implies that paraffin or frozen sections must be prepared before FISH analysis. However, the procedure for the preparation of paraffin sections is lengthy and includes dehydration, embedding in paraffin, sectioning, mounting onto a glass slide and rehydration; all these steps require efficient techniques. On the other hand, the procedure for the preparation of frozen sections is simpler, but the resolution of these sections is usually lower than that of paraffin sections. In addition, the use of the sectioned tissues restricts the range of observation to a specific area: only a limited number of cells can be observed at any given time by analyses of the tissue sections, and sectioning also restricts observations to a particular plane. Thus, it is difficult to obtain results that reflect the characteristics of whole tissues by performing FISH studies in tissue sections.

To solve these problems, we attempted hybridization with fluorescence-labeled probes on the whole gill filament of bathymodiolin mussels without sectioning to visualize the distribution of the symbionts. By using this technique, we examined a large area of the epithelium for the presence of symbionts and avoided the lengthy sectioning process.

\section{MATERIALS AND METHODS}

\section{Sample collection}

Bathymodiolus septemdierum harboring thiotrophic endosymbionts (Fujiwara et al. 2000, Koito et al. 2010a) were collected at a depth of $1237 \mathrm{~m}$ from the hydrothermal vent located in the caldera of Myojin Knoll, Izu Islands, Japan, in April 2008 during research cruise NT08-07 of RV 'Natsushima'. Samples of the related species $B$. platifrons, which harbor methanotrophs (Fujiwara et al. 2000, Koito et al. 2010b), were also obtained during the Natsushima cruise NT08-24 in December 2008 at a depth of $900 \mathrm{~m}$ from a methane seep in Sagami Bay, Japan. The mussels from both cruises were collected using a suction sampler loaded onto the remotely operated vehicle (ROV) 'Hyper-Dolphin', operated by the Japan Agency for Marine-Earth Science and Technology. These 2 species were chosen because they are good models for studying symbiosis between chemosynthetic bacteria and invertebrates. Also, they are dominant at the collection sites, easily obtainable (Hashimoto \& Okutani 1994) and can be reared for several months at atmospheric pressure in the laboratory (Fujiwara et al. 1998, Koito et al. 2010b). After sampling, the mussels were kept in chilled seawater at $4^{\circ} \mathrm{C}$ and subjected to dissection within $5 \mathrm{~h}$.

\section{FISH procedure}

DNase/RNase-free reagents were purchased from a commercial source (Wako Pure Chemical) and used for fixation and hybridization. The central part of the gills, consisting of 10 to 20 gill filaments, was dissected on ice by using fine scissors and fixed for 12 to $24 \mathrm{~h}$ in $4 \%$ paraformaldehyde in phosphate-buffered saline ( $\mathrm{PBS}_{i} \mathrm{pH} 7.4$ ) at $4^{\circ} \mathrm{C}$, and then stored at $4{ }^{\circ} \mathrm{C}$ in $70 \%$ ethanol during the cruise. A single gill filament was isolated by cutting the blood vessel at the basal part of the filaments with fine forceps and a surgical knife. More than 10 filaments for each of 5 mussels for each species were collected. Each filament was washed with water and transferred to a $1.5 \mathrm{ml}$ microcentrifuge tube containing a solution of $20 \mathrm{mM}$ tris-hydrochloric acid (tris- $\mathrm{HCl}, \mathrm{pH} 7.4$ ), $0.9 \mathrm{M}$ sodium chloride $(\mathrm{NaCl}), 5 \mathrm{mM}$ EDTA, $0.01 \%$ sodium dodecyl sulfate (SDS), 0 to $50 \%$ (v/v) formamide and $50 \mu \mathrm{g} \mathrm{ml}^{-1}$ of one of the following Cy3-labeled probes: Bsob692 (5'-CGC CATT GAT GTT CCT TCA G-3'), a specific probe for thiotrophic symbionts of bathymodiolin mussels (Fujinoki et al. 2011), or Bmob641 (5'-GTT TTA AAT GCA GTT CCC AG-3'), a newly designed probe to detect methanotrophic endosymbionts of bathymodiolin mussels. The tubes were incubated for 2 to $4 \mathrm{~h}$ at $46^{\circ} \mathrm{C}$ (Suzuki et al. 2006). After hybridization, the samples were washed at $48^{\circ} \mathrm{C}$ for $30 \mathrm{~min}$ in a solution containing all the above-mentioned components of the hybridization solution, except the probes and formamide. The stringency of washing was adjusted by $\mathrm{NaCl}$ concentration according to the method described by Lathe (1985). Finally, the filaments were stained with $0.4 \mu \mathrm{g} \mathrm{ml}^{-1}$ of DAPI for $10 \mathrm{~min}$, washed briefly with PBS and mounted with Vectashield mounting medium (Vector Laboratories) on a glass slide. DAPI stains both host and symbiont DNA, and thus the signal that is labeled by DAPI but not by symbiont-specific probes is recognized to be derived from the host DNA. 


\section{Microscopic observation}

The hybridized and stained filaments were observed under a Zeiss Axioplan 2 fluorescent microscope (Carl Zeiss). Cy3 and DAPI fluorescence were detected by G and UV excitation, with Zeiss01 and Chroma HQ41007 filters, respectively. For detailed analyses, image data were obtained and recorded with a FV500 confocal laser microscope (Olympus, Tokyo, Japan). The micrographs were saved in tagged image file format (TIFF).

\section{RESULTS AND DISCUSSION}

The representative fluorescent micrographs of the surface of the gill filaments of Bathymodiolus septemdierum are shown in Fig. 1a-d. As expected, a large area of the lateral surface of a gill filament can be examined at a time. For example, the fields of vision in Fig. 1a,b correspond to more than 80 serial tissue sections of $10 \mu \mathrm{m}$ thickness. The fluorescent signal was observed as particles, which are identified as bacteriocytes because their size corresponds to that of bacteriocytes previously reported (Fujiwara et al. 2000). Most parts of the lateral surface consisted of bacteriocytes that fluoresced (Fig. 1a,c). In contrast, the ciliary cells lining the frontal surface of the gill filament did not exhibit fluorescence; this finding indicates the absence of the symbionts in this area and is consistent with previous bathymodiolin mussels observed under a transmission electron microscope (Fiala-Médioni et al. 1986). Band-like zones, in which fluorescence was not detected, were observed in all the filaments (Fig. 1a,c). These zones corresponded to the ciliary junctions that were detected in B. thermophilus (Raulfs et al. 2004). Ciliary cells, which appeared as dark regions on the FISH micrograph, were brightly stained by DAPI. These results indicated that the ciliary junction consisted of host cells, which lacked the thiotrophic symbiont (Fig. 1b,d).

The methanotrophic symbionts in Bathymodiolus platifrons was also detected (Fig. 1e-h) by using the methanotroph-specific probe Bmob641 designed for this study: wide distribution of bacteriocytes on the lateral surface of the gill filaments were revealed under the fluorescent microscope (Fig. 1e,g). However, instead of band-like dark zones, oval areas lacking fluorescence were observed. These areas were thought to correspond to ciliary tufts found in Bathymodiolus sp., as reported by Fiala-Médioni et al.
(1986). DAPI staining revealed that the oval areas contained host DNA (Fig. 1f,h). Thus, the ciliary tufts also consist of the host cells with no metanotrophic symbionts.

The confocal laser scanning microscope enables observation at higher magnification (Fig. 2a-f). In the case of Bathymodiolus septemdierum, most bacteriocytes were rather large, polygonal cells that appeared in close proximity to one another (Fig. 2a). In contrast, in B. platifrons gills, bacteriocytes appeared smaller and rounder and seemed to be detached from one another (Fig. 2d). The difference in the size and shape of bacteriocytes between the 2 species is not an artifact that can be attributed to the difference of the depth of planes because we also checked different depths, and our results are consistent with the previous study that used transmission electron microscope (Fujiwara et al. 2000, Barry et al. 2002). The distribution of the nuclei of the host cells was visualized with DAPI staining (Fig. 2b,e). The host nuclei of the bacteriocytes were not always clearly visible in both species because of the overlap of the signals from the bacterial DNA with those of the host nuclei. In contrast, the nuclei of intercalary cells located between the bacteriocytes were clearly detected (Fig. 2b,c,e,f).

Thus, we established a technique to examine the distribution of symbiotic bacteria in whole gill filaments, which enabled us to observe a wide area and avoid a lengthy sectioning process. In addition, it is expected that quantitative and 3-dimensional analyses are possible with a confocal laser-scanning microscope and appropriate image analysis software. We expect that the technique will be used in the examination of the distribution and abundance of symbionts in the tissues of deep-sea mussels, as well as be used to observe their changes under the different environmental and physiological conditions of the hosts. In addition, it is expected that the technique will be applicable to other species harboring symbionts in the gills. The gill filaments, which mainly consist of a monolayer of epithelium, are a suitable target of this technique. However, we expect that the use of a confocal laser-scanning microscope will enable researchers to apply this technique to multilayer tissues if the probe can penetrate to the target cells.

Acknowledgements. We thank the crew of RV 'Natsushima' and ROV 'Hyper-Dolphin' for their support during the cruises NT08-07 and NT08-24. This work was supported by KAKENHI (Nos. 19380110 and 22380107). 

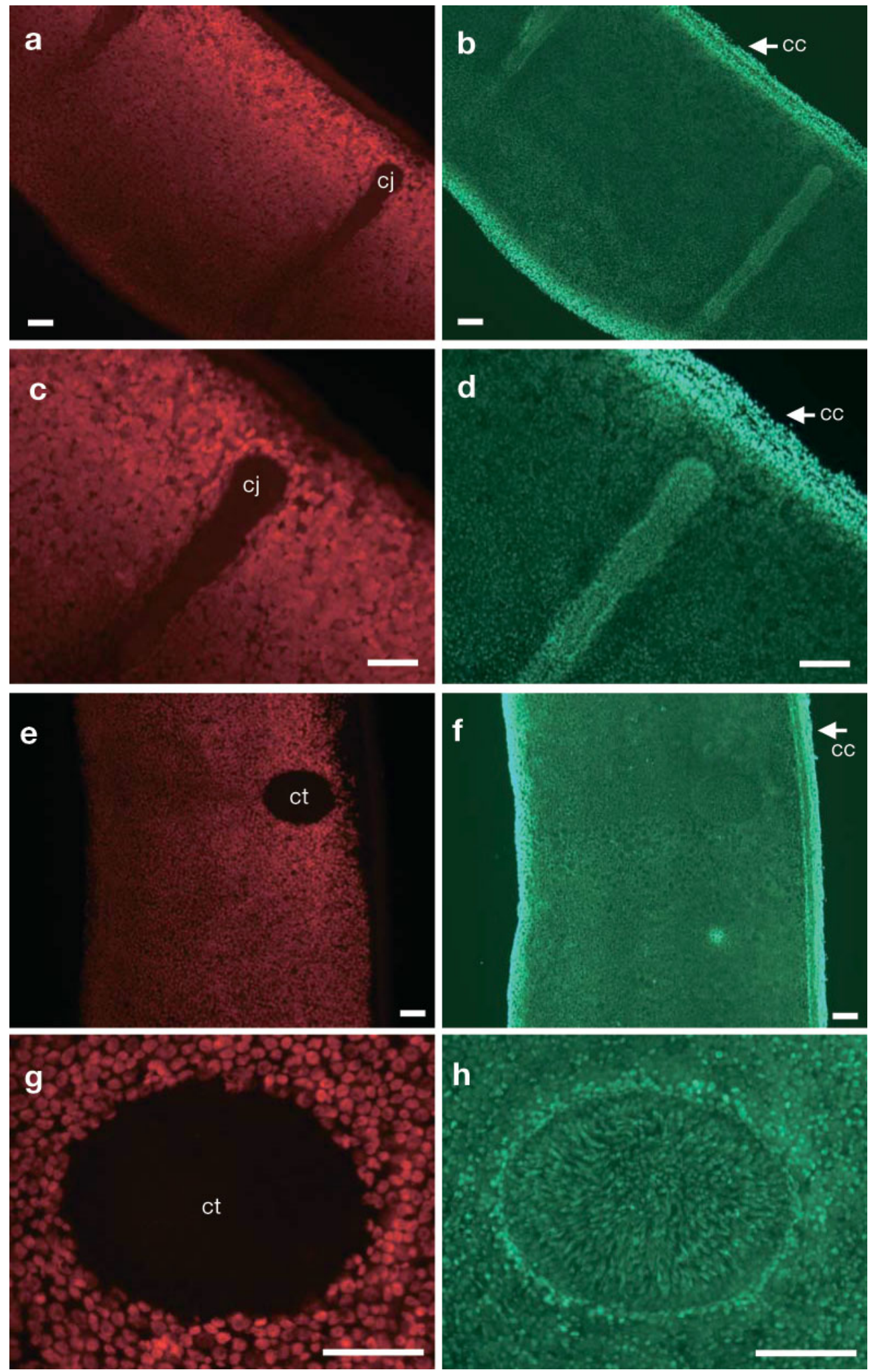

Fig. 1. Bathymodiolus septemdierum and B. platifrons. Fluorescent micrographs of whole-mount fluorescence in situ hybridization (FISH) on the gill filaments of 2 deep-sea mussels: (a-d) B. septemdierum and (e-h) B. platifrons. (a,c) Fluorescent signal with Bsob692. (e,g) Fluorescent signal with Bmob641. (b,d,f,h) Results of DAPI staining. cc: ciliary cells lining the frontal surface; cj: ciliary junction; ct: ciliary tuft. Scale bars $=100 \mu \mathrm{m}$ 

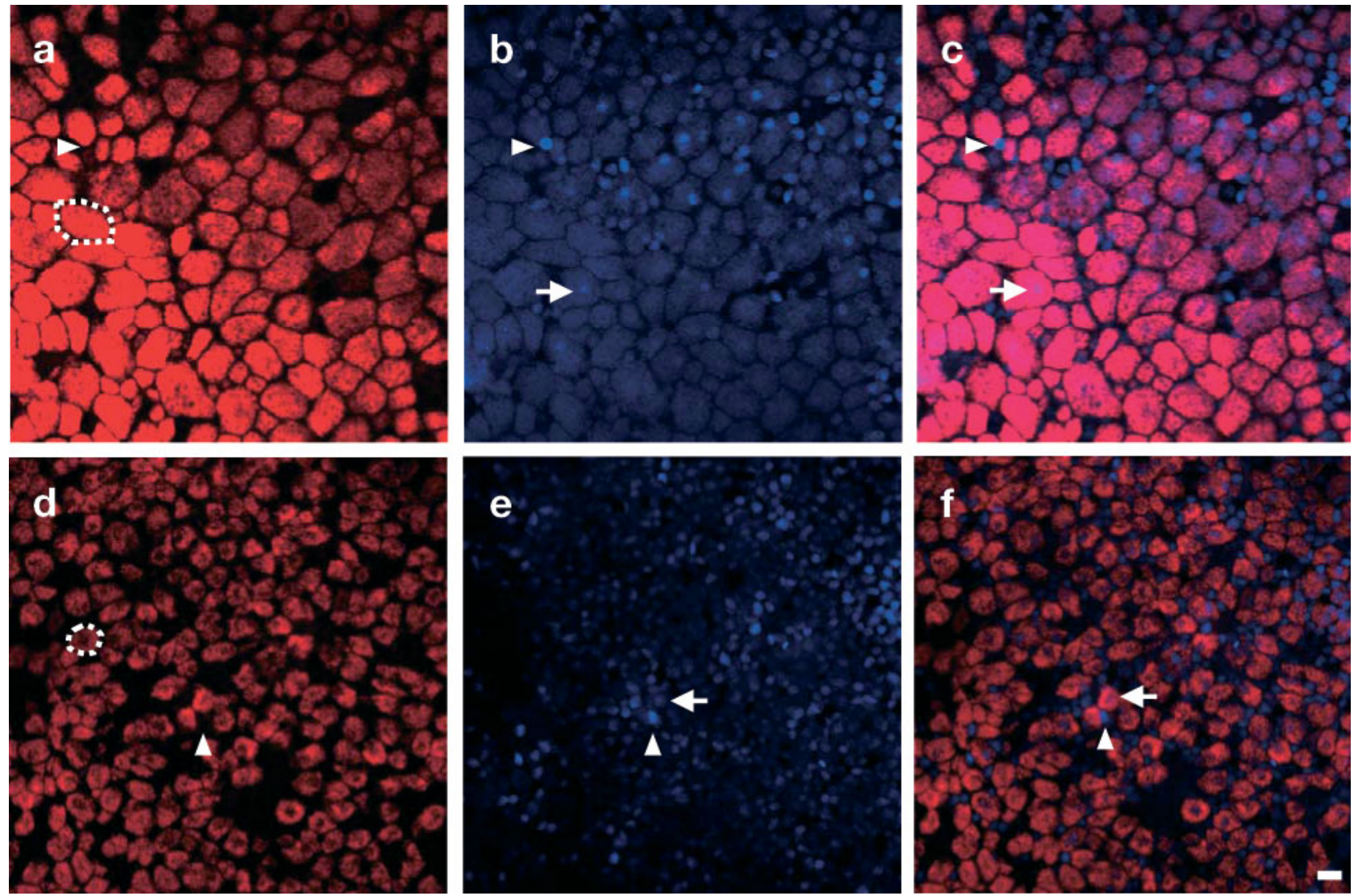

Fig. 2. Bathymodiolus septemdierum and B. platifrons. Fluorescent micrographs of whole-mount fluorescence in situ hybridization (FISH) on the gill filaments of 2 deep-sea mussels: $(\mathrm{a}-\mathrm{c})$ B. septemdierum and (d-f) B. platifrons. The areas containing no ciliary cells were chosen for observation. The micrographs were taken on a confocal laser scanning microscope. (a,d) Fluorescent signals with Bsob692 and Bmob641, respectively. (b,e) Results of DAPI staining. (c) Merged image of panels (a) and (b); (f) merged image of panels (d) and (e). A typical bacteriocyte is indicated with a dashed line in panels (a) and (d). Arrows and arrowheads indicate the host nuclei of the intercalary cells and bacteriocytes, respectively; the position of the intercalary cells is recognized as the gap between bacteriocytes in panels (a) and (d). Scale bar (for all panels) $=10 \mu \mathrm{m}$

\section{LITERATURE CITED}

> Amann RI, Ludwig W, Schleifer KH (1995) Phylogenetic identification and in situ detection of individual microbial cells without cultivation. Microbiol Rev 59:143-169

> Barry JP, Buck KR, Kochevar RK, Nelson DC, Fujiwara Y, Goffredi SK, Hashimoto J (2002) Methane-based symbiosis in a mussel, Bathymodiolus platifrons, from cold seeps in Sagami Bay, Japan. Invertebr Biol 121:47-54

$>$ Bouvier T, Del Giorgio PA (2003) Factors influencing the detection of bacterial cells using fluorescence in situ hybridization (FISH): a quantitative review of published reports. FEMS Microbiol Ecol 44:3-15

> Duperron S, Sibuet M, MacGregor BJ, Kuypers MMM, Fisher CR, Dubilier N (2007) Diversity, relative abundance and metabolic potential of bacterial endosymbionts in three Bathymodiolus mussel species from cold seeps in the Gulf of Mexico. Environ Microbiol 9: 1423-1438

> Fiala-Médioni A, Métivier C, Herry A, Le Pennec M (1986) Ultrastructure of the gill of the hydrothermal-vent mytilid Bathymodilus sp. Mar Biol 92:65-72
Fujinoki M, Koito T, Nemoto S, Kitada M and others (2011) Comparison of the amount of thiotrophic symbionts in the deep-sea mussel Bathymodiolus septemdierum under different sulfide levels using fluorescent in situ hybridization. Fish Sci 78:139-146

Fujiwara Y, Uematsu K, Tsuchida S, Yamamoto T and others (1998) Nutritional biology of a deep-sea mussel from hydrothermal vents at the Myojin Knoll Caldera. JAMSTEC J Deep Sea Res 14:237-244 (in Japanese)

> Fujiwara Y, Takai K, Uematsu K, Tsuchida S, Hunt JC, Hashimoto J (2000) Phylogenetic characterization of endosymbionts in three hydrothermal vent mussels: influence on host distributions. Mar Ecol Prog Ser 208: $147-155$

Hashimoto J, Okutani T (1994) Four new mytilid mussels associated with deepsea chemosynthetic communities around Japan. Venus 53:61-83

Koito T, Morimoto S, Toyohara H, Yoshida $\mathrm{T}$ and others (2010a) Decline in taurine transporter mRNA and thioautotrophic bacterial 16S rDNA levels after transplantation of the hydrothermal-vent mussel Bathymodiolus septemdierum to a non-vent position. Cah Biol Mar 51:429-433 
Koito T, Nakamura-Kusakabe I, Yoshida T, Maruyama T, Omata T, Miyazaki N, Inoue K (2010b) Effect of longterm exposure to sulfides on taurine transporter gene expression in the deep-sea mussel Bathymodiolus platifrons, which harbors a methanotrophic symbiont. Fish Sci 76:382-388

Lathe R (1985) Synthetic oligonucleotide probes deduced from amino acid sequence data. Theoretical and practical considerations. J Mol Biol 183:1-12

Editorial responsibility: Christine Paetzold, Oldendorf/Luhe, Germany
Raulfs EC, Macko SA, Van Dover CL (2004) Tissue and symbiont condition of mussels (Bathymodiolus thermophilus) exposed to varying levels of hydrothermal activity. J Mar Biol Assoc UK 84:229-234

Suzuki Y, Kojima S, Watanabe H, Suzuki M and others (2006) Single host and symbiont lineages of hydrothermal-vent gastropods Ifremeria nautilei (Provannidae): biogeography and evolution. Mar Ecol Prog Ser 315: 167-175

Submitted: February 24, 2010; Accepted: October 13, 2011 Proofs received from author(s): December 16, 2011 